\title{
Youth Unemployment Challenges and Opportunities: the Case of Sierra Leone
}

\author{
Molla Mekonnen Alemu ${ }^{1}$ \\ ${ }^{1}$ Texila American University, Guyana. \\ Correspondence: Molla Mekonnen Alemu, Texila American University, Guyana.
}

Received: July 18, 2016

Accepted: August 9, 2016

Available online: August 18, 2016

doi:10.11114/ijsss.v4i10.1818

URL: http://dx.doi.org/10.11114/ijsss.v4i10.1818

\begin{abstract}
Sierra Leone has gone through a ten-year civil conflict which brought considerable destruction, on the livelihoods of many. A good percentage of the population, before the war, was composed of young men and women who provided the labour force for activities on the farms. These youth (15-35 years of age) have undergone serious transformations as a result of the civil conflict. Most of them have got themselves completely disoriented. About $60 \%$ of the country's youth are believed to be structurally unemployed. The study was aimed at assessing the main causes of youth unemployment in Sierra Leone and to develop sustainable employment strategic principles which will enhance the management of youth employment opportunities in the country. Primary data were collected through structured questionnaire and semi-structured interviews. Different reports, policy papers and publications were also reviewed. Legacy of the civil war, mismatch between the demand and supply side of labour, weak entrepreneurship services, rural to urban migration, and low level of involvement in agriculture were among the identified factors that aggravated the youth unemployment rate in the country. The study has also identified strategic directions which could help policy and decision makers in their effort for the development of the youth of the country.
\end{abstract}

Keywords: youth, unemployment, strategy, development

\section{Introduction}

The future of Africa is projected to have a bumpy road as the continent needs to coupe up with the ever increasing depletion of its natural resources, global warming, population growth and the heightened urgency to create the livelihoods development enabling environment in a sustained manner (Babatunde, 2014).

The non-inclusive trends of Africa's growth and development models is highly dominated by capital intensive sectors that grant little or no benefit to the wider portion of the society that possess a huge potential in terms of labour force supply. The current economic growth of Africa is not in a position to increase the capacity of its human capital through the development of employment opportunities specifically for the marginalized youth and women (AFDB, 2012).

The National Youth Policy of Sierra Leone and the National Youth Commission Act of 2009, defined youth as 'all Sierra Leonean female and male between the ages of 15 and 35'. This segment of the nation is being challenged with a multitude of issues that requires economic, political and social supports (GoSL, 2003).

The total population of Sierra Leone is estimated to be 5.9 million, of this 60 percent lives in rural areas. According to national statistics, 34 percent of the total population falls under the category of youth. Furthermore, 44 percent of the country's population falls under the age of 15 and the youthful population of the country is expected to be high in the years to come. The adolescent category (15-19) is about 11 percent of the population, while those between the ages of 20-24 account 8 percent (NAYCOM, 2012).

The eleven years civil which lasted in 2002 took the lives of about 50,000 Sierra Leoneans, dismantled livelihood opportunities, and also destroyed various infrastructures like schools, Universities, health facilities, roads, etc. which were meant for the wellbeing and development of the nation (NAYCOM, 2012).

Even though, the recovery for development programmes and efforts of different development partners have tried to rehabilitate the wellbeing of the nation, Sierra Leone is still among the poorest countries of the world. According to the United Nations Development Programme Human Development Index, in 20012 Sierra Leone was rated 180 out of 187 countries, 179 out of 187 countries in 2012 and 183 out of 187 countries in the year 2013 (UNHDI, 2014). 
About $60 \%$ of young Sierra Leoneans are also believed to be structurally unemployed and this rate is among the highest in the sub-region of West Africa. In addition to this, even with in the region, the country is believed to have the highest rate of underemployment among the youth that are earning less than $\$ 1$ per day. A greater proportion of the 'working youth' are still living in extreme poverty and more than 80 percent of young Sierra Leoneans are earning below the poverty line of $\$ 2$ per day. This is attributed to the 11 years civil war, poverty, weak private sector as a result of legacy of the civil war, low level of coordination to create employment opportunities and the skills mismatch between the growing private sector and the old aged curriculum (UN, 2007 cited in NAYCOM, 2012).

\subsection{Objectives of the Study}

The overall aim of this work is to assess the main causes of youth unemployment in Sierra Leone and to develop sustainable employment strategic principles which will enhance the management of youth employment opportunities in the country.

\section{Method}

\subsection{Description of the Study Area}

The Republic of Sierra Leone is located on the west coast of Africa. The country with a total area of 71,740 square kilometers, shares border with Guinea in the north-east and with Liberia in south-east. The south-west part of the country is bordering with the Atlantic Ocean. Topographically, the country holds a huge amount of flat land and the coastal swampy plains are predominantly covered by mangrove forests. The country also receives an average of 3,434mm of rainfall per annum (NGS, 2015).

The population of the country is about 5,865,881 million, with 5.6 average size of household. The main source of livelihood $(59.7 \%)$ for the major portion of household heads comes from agriculture and fishery activities. Entrepreneurship activities also play a pivotal role for the livelihoods of about $18.5 \%$ of household heads (SSL and UNDP, 2014).

The country's economy is mainly dominated by the production of primary commodities, primarily agricultural and mineral production systems. As the country is rich with mineral resources, mining is expected to contribute $30 \%$ of the country's GDP by 2017 as a result of the expansion of the private sector in the extractives sector.

Agricultural activities, which includes forestry and fisheries sector takes the largest contribution to the GDP share. However, this contribution to the GDP declined from 52\% in 2011 to $42 \%$ in 2013 as a result of the expansion of the mining sector. In spite of this fact, the agriculture sector still remains to be the major source of employment, accounting to more than $70 \%$ of the labour force of the country (NAYCOM, 2012; AfDB, 2013).

The extractives sector on the other hand, though it is the growing source of revenue for the country, it only contributes for less than $3 \%$ of the labour force since it highly depends on skilled labor which mainly comes from other countries. The service sector which includes retail trade, banking, tourism and transport contributed $28 \%$ of the GDP in 2013 by dropping down from the $35 \%$ contribution in 2011 . The manufacturing sector on the other hand is largely dominated by the production of cement and light scale consumer goods and services contributed only $2 \%$ of the GDP in 2012 as a result of poor infrastructure, energy supply and weak marketing facilities and linkages. The exploration of oil and natural gas is still ongoing even though the hope of getting a commercially viable source is very minimal (NAYCOM, 2012; AfDB, 2013).

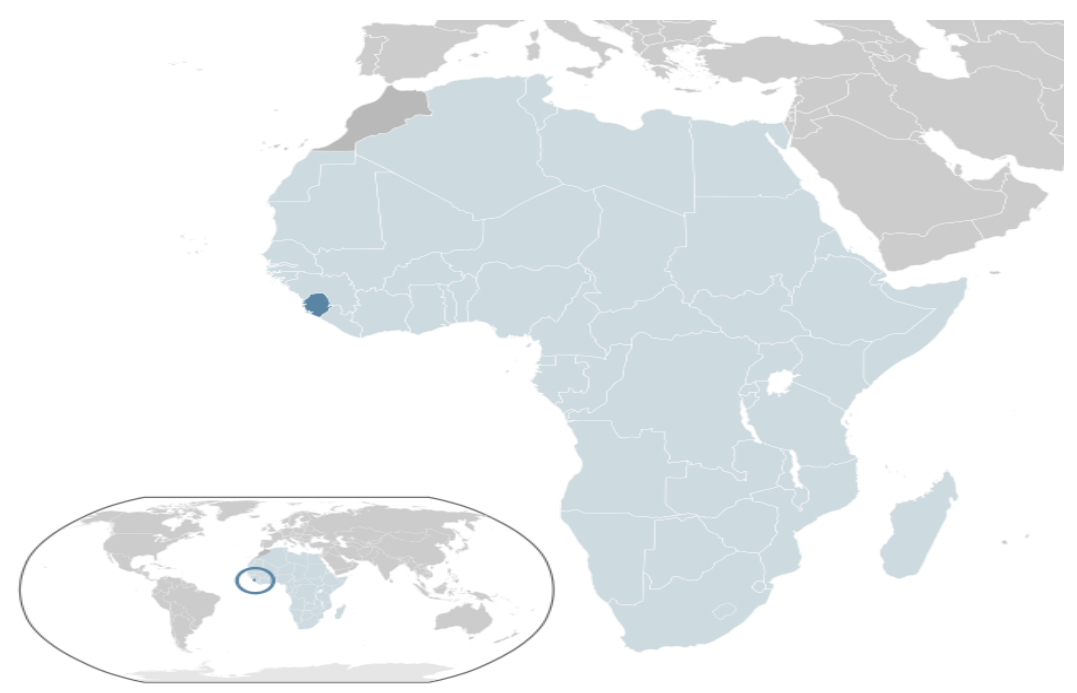

Figure 1. Location Map of Sierra Leone 


\subsection{Data Collection and Analysis}

This study focuses on assessing the major factors that are affecting youth employment opportunities and develop a strategic principles and directions to overcome these challenges. In order to address the research objectives a mix of methods (interviews, questionnaires, focus group discussions, textual analysis, and observations) were deployed in the data collection and analysis process.

\subsubsection{Questionnaires}

A semi-structured questionnaire was used as one of the methods to collect primary data. Questionnaires are one of the most widely used techniques in social research. Using questionnaires is an obvious strategy for finding the answers to the issues that matter and can provide straight forward descriptive information about the questions (Todd, 1979; Blaxter et al., 2001; Munn and Drever, 1990; Adams and Schvaneveldt, 1991). The research used the questionnaire to collect the primary information on the challenges and opportunities of employment from the different segments of youthful population.

\subsubsection{Interviews}

In their commentary on the types of interviews, Siraj-Blatchford I. and Siraj-Blatchford J. (2001) contend that interviews can be entirely structured, entirely unstructured or semi-structured. They claimed that unstructured interviews often referred to as 'conversation with a purpose', are considered to provide the respondents with maximum freedom in determining their response.

Opportunities arise during an interview so that the interviewer can probe answers and use prompts to encourage and expand responses (Siraj-Blatchford and Siraj-Blatchford, 2001). This will add significance and depth to the data obtained (Saunders et al., 2000, Robson 2002). Officials from different development agencies and youth serving institutions were interviewed on the issues that are affecting the employment opportunities of young Sierra Leoneans.

\subsubsection{Textual Analysis}

A desk review of documents relating to the youth development opportunities and challenges was also conducted. Policy papers, strategic documents, plans and project documents were reviewed so as to get a better insight and perception of the subject. This has enabled the researcher to sift through different secondary information so as to explore the focus of institutions, individuals, groups, or social attention in order to address youth unemployment (Weber, 1990). Krippendorff and Mary (1990) contend that this type of analysis is useful for examining trends and patterns in documents (Weber, 1990).

\subsubsection{Observation}

In the process of the data collection exercise, observation of the subject matter under research was a central attention to the researcher. This has enabled to verify the information collected is comprehensive, well-developed and captured the different dimensions in which the research is focusing at (Cohen, 2006).

In line with this, a total of 7 ( 2 female) youth serving development partner agency representatives, 8 ( 3 female) youth serving Government institution representatives and 162 youth (39 female) from five districts (Bo, Makenie, Kenema, Freetown urban and Newton) were considered in the data collection process. The collected data was analyzed through qualitative research analysis method based on the type of methods used to collect the data. The primary information collected through interview, observation and questionnaire was separately transcribed. The transcription helped the collected result to be ready for scientific analysis. Then content analysis of respondents (individual and group) opinion, view, and perspective in interview and the physical setting in observation was made and main points were analysed (Roulston, 2001; Boeije, 2010; Flick et al., 2004). SPSS was also used in order to analyze the quantitative information. In addition to this, different legal and policy documents which are related to youth development areas were analyzed by using the key words from the framework of this research.

\section{Results}

\subsection{Global Trends of Unemployment}

In the last two decades remarkable achievements were achieved in combating poverty in a global scale. However, for the even distribution of the benefits of economic growth among the poor, a lot of work has to be done. This could include the creation of the enabling environment for the poor and marginalized young group to have access to livelihood opportunities, access to micro finance, skills development, etc. (Andrew and Andrew, 2012; Eastwood and Lipton 2000; Kakwani, Neri, and Son 2004).

In line with this, it is also well known that, the fare distribution of economic benefits is closely linked with the amount and quality of new employment opportunities and with the challenges that prohibit the poor and marginalized group 
from taking advantage of the prevailing opportunities. It is also a common fact that, the lion share of the global population, specifically the poor, is highly dependent on their physical labor in order to make their living earning incomes (Pierella and Pieter, 2007). Of current developing country workers, over one-third in South Asia and over one-half in Sub-Saharan Africa are earning less than \$1 per day. For this segment of the population employment opportunities never came with a solution to break the bondage of poverty. In addition to this, these low skilled and low-payed workers are going through worsening circumstances of their incomes as compared to skilled workers, which is again part and parcel of the wider global inequality among the poor and the rich that was observed since 1980. This phenomenon prompted many to generalize as the development of economy alone cannot ensure the improvement of employment opportunities for the different segments of a society and often the negative impacts of globalization sends a clear signal for the development of policy and strategic actions that will enhance employment opportunities (DFID, 2008).

As compared to the year 2012, global unemployment rose by 5 million people in 2013 (Figure 2). It is estimated that, globally more than 202 million people were unemployed, implying as employment opportunities are not expanding as compared to the ever growing supply of the global labor force (ILO 2014).

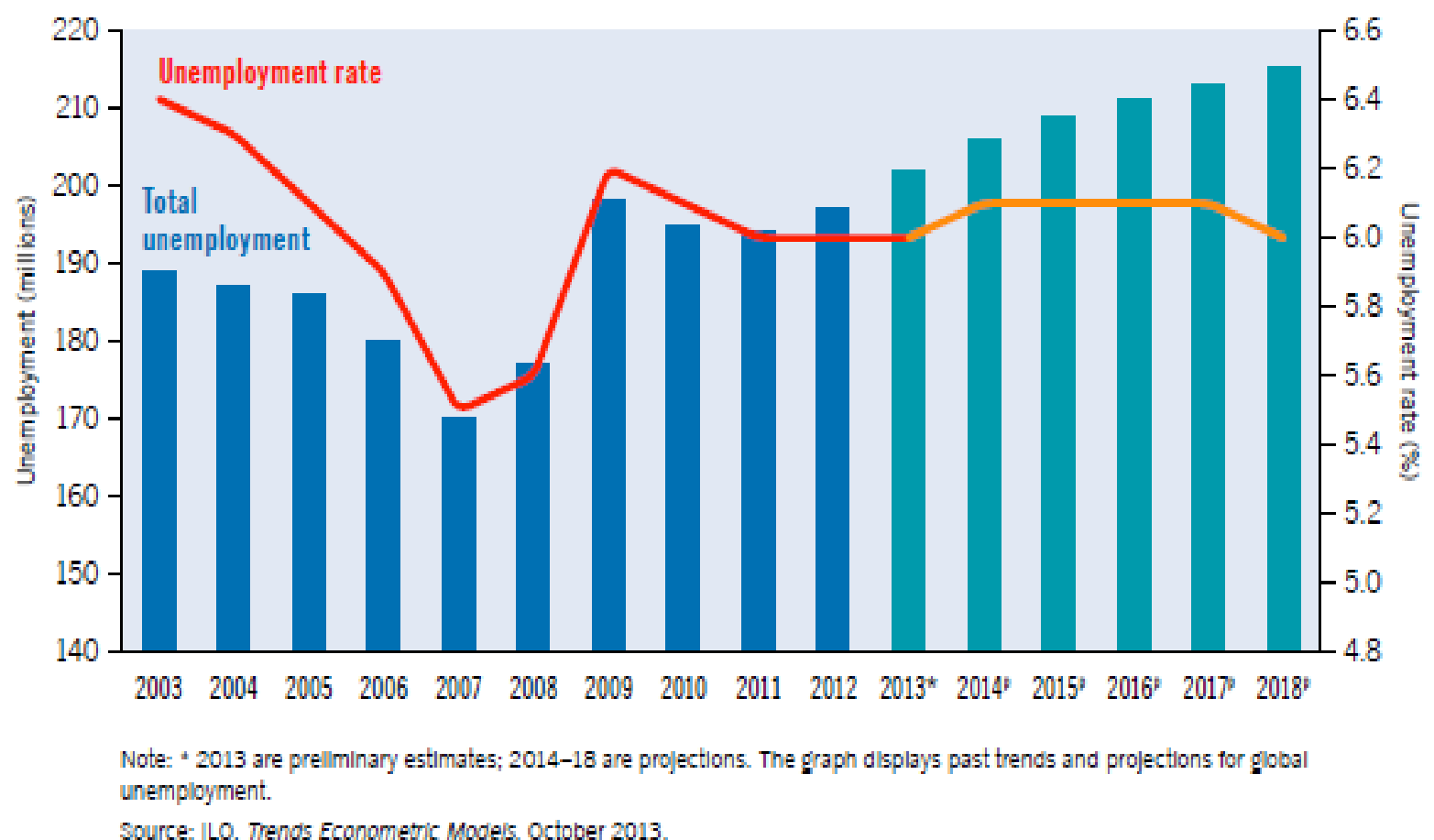

Figure 2. Global Unemployment Trends and Projections, 2013 - 18

The state of youth labor market is worsening in almost every part of the world. Globally, the rate of youth unemployment reached to 13.1 percent in the year 2013 from the 12.9 percent of 2012 and the 11.6 percent of 2007. The greatest increase of unemployment occurred among the youth of the Middle East region as it happen to have the largest youth unemployment rate of the world by accounting about 27.2 percent in 2013 in contrast with 26.6 percent in 2012. Similarly, Central and South-Eastern Europe, South-East Asia, East Asia, the Pacific and North Africa regions have also experienced a significant development of unemployment rates (Figure 3). Even in the developed world, the region that showed the highest increment of unemployment among the youth in the years between $2007-12$, still unemployment rate increased to 18.3 percent among youth (ILO 2014). 


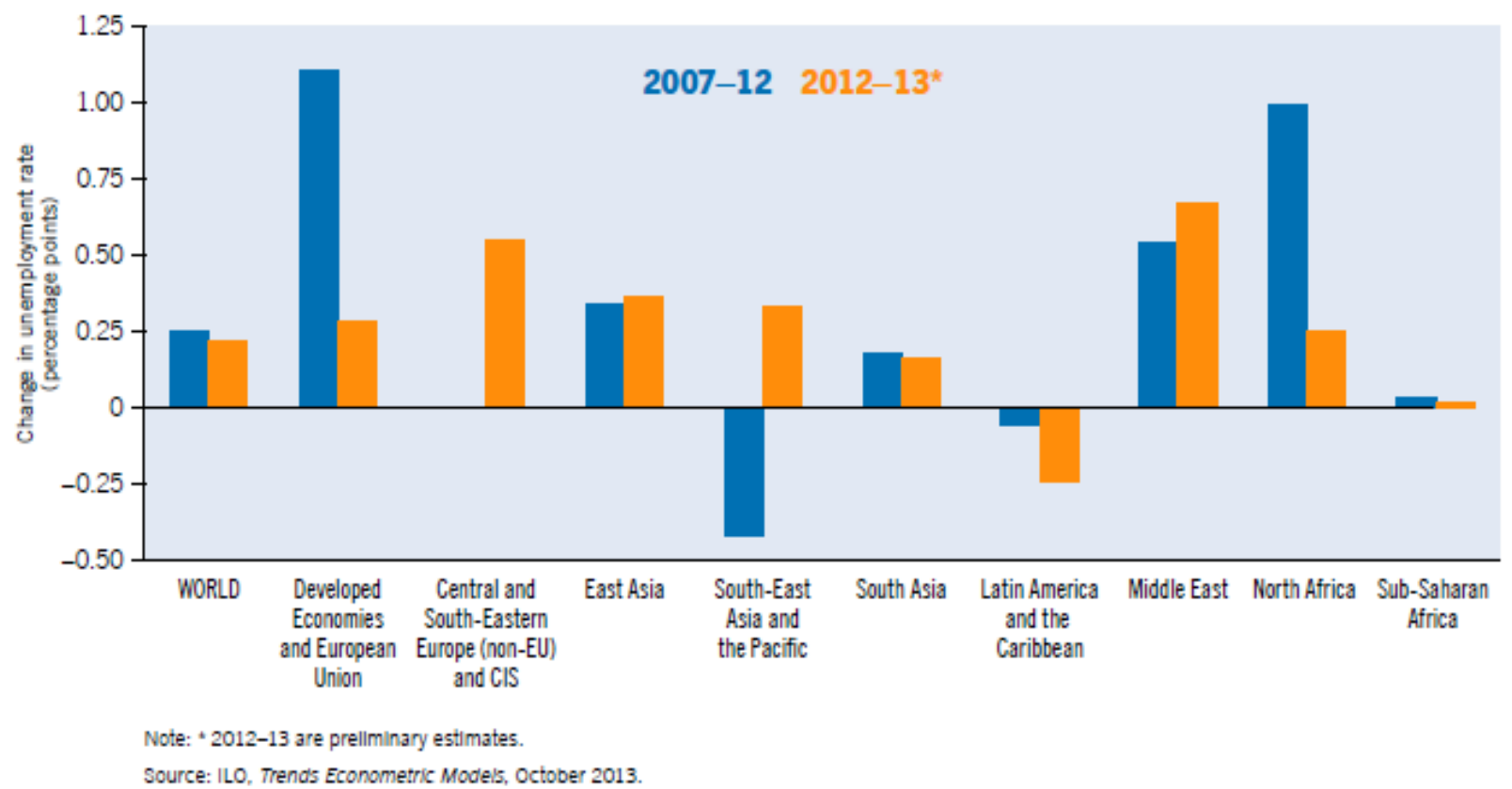

Figure 3. Average Annual Change in the Youth Unemployment Rate, Selected Time Periods (Percentage Points)

East Asia and South Asian regions also registered a huge increase for the global unemployment rate that accounts for about 45 percent addition to the job seeking market, followed by the Sub-Saharan region of Africa and Europe. Contrary to this, the Latin Americas only added fewer than 50,000 additional jobseekers to the global statistics, which is about an increase of 1 percent to the 2013 unemployment rate. It is also estimated as the global youth unemployment would rise by 13 million by the year 2018. It is also assumed that, given the current trends of global unemployment, there will be more than 215 million unemployed people by the year 2018 (ILO 2012, 2014). This all is attributed as a result of inefficient pro-poor growth and development policy and strategies that are not designed to encourage youth employment opportunities (AfDB 2011, ILO 2014).

It is also reported that more than one-third of the labor force found in the developing world is self-employed and also estimates shows that $10-12 \%$ of same region is getting employment opportunities from family related household enterprises. For many years, self-employment opportunities were regarded as a self-help safety net option in countries which doesn't observe government-sponsored safety net opportunities (Christopher Woodruff, 2007).

In countries which have a growing economy, the availability of a growing labor force can help to maintain labor related costs in its minimum and perhaps can boost labor-intensive growth and development. Whenever there are challenges in development as the case of most developing countries, an increment of labor supply reveals itself predominantly in lower wages and higher unemployment rates among the young people. 'Youngsters' lack of on-the-job experience makes them less productive than the average "prime-age" worker and thus more liable to be unemployed during periods of recession. In every region of the world, the difficulty youth face in entering the labor market is evident in higher than average unemployment rates' (DFID, 2008).

Youth unemployment is a prime and major component of the overall unemployment and this is very true in the context of Africa. Based on the present day growth and development trends, and the current growth trends of the youthful labor force, it is estimated that, the demand and supply sides of the labor force may finally catch up after 2050 (DFID, 2008).Yet, if growth and development needs to be inclusive, a greater intensity of livelihood opportunities have to maintained in a sustainable manner which covers different sectors and all segments of the society. The lion's share of the livelihood opportunities in Africa is highly reliant on the natural resource bases. For instance, more than $80 \%$ of Africans are dependent on agriculture, extractives, forestry and fishing activities (UNESEC, 2011). Therefore, exploring the great potentials of the continent by making use of its rich natural resources will help to develop its human, economic and social capitals by maximizing the sustained growth and development of employment potentials.

\subsection{Sierra Leone National Youth Policy}

The vision of the National Youth Policy of Sierra Leone is to create the enabling environment for the development of female and male young people by empowering their capabilities so that they will be able to contribute for the betterment 
of the country. It is also aimed at paving the way for the sustained implementation of youth empowerment and development programmes.

The policy is formulated based on the basic guiding principles of the Commonwealth Plan of Action for Youth Empowerment. The policy also makes use of the youth rights approach for the development and empowerment of the youth that is aimed at mainstreaming the rights of the youth as indicated in the Constitution of the country, the Education Policy of the country, the United Nations Convention on the Rights of the Child and the Lisbon Protocol of 1998 (GoSL, 2014).

The major emphasis of the National Youth Policy is to tackle the main challenges being faced by the youth of the nation which includes youth unemployment and under-employment, skills mismatch between the demand and supply side of the work force, access to quality education, ethics, drug and related substances, gender inequality and disparity, participation in decision making processes, and sexual and reproductive health challenges of girls. In addition to these, the policy also provides an outlook for the proper assessment, design, implementation, monitoring, coordination and evaluation frameworks of youth development initiatives which will be implemented by Government institutions, development partners, youth associations, Civil Society Organization and other partners of the youth sector.

The global rate of unemployment is increasing at an alarming rate partly due to the economic recession which faced the world. It is estimated that about 1.4 billion people are living under the bondage of poverty throughout the world. The prevalence of poverty is life-threatening and the poor can hardly manage to survive. It is believed that more than 25,000 of them die as a result of hunger in each day while a new billionaire is being created in every second day (GoSL, 2014).

In Sierra Leone youth are facing manifold challenges which include obtaining decent employment opportunities, mainly among rural youth (NAYCOM, 2012; GoSL, 2014).

Shortage of employable skills as a result of the mismatch between the demand and supply side of the work force, lack of work experience (even internship opportunities), low level of education among the youth, etc. are some of primary challenges that aggravated the youth unemployment rate in the country.

Apart from these, as a result of the legacy of the civil war, the present day young people are facing a high level of inactivity, unemployment and under-privileged working conditions characterized by low wages and long working hours. Poor quality of education, poor health facilities, spread of HIV/AIDS, the ever increasing teenage pregnancy and drug abuse are also among the challenges that affect the quality of young people's life in the country (NAYCOM, 2012; GoSL, 2014; GoSL and UNDP, 2014).

More than $60 \%$ of youth in Sierra Leone are either unemployed or underemployed and more than $50 \%$ of the country's youth are believed to be either illiterate and/or unskilled. The youth unemployment can vividly be felt in the streets of the capital and also in other regional cities (NAYCOM, 2012; GoSL, 2014; GoSL and UNDP, 2014).

The findings of the research have shown that many factors and conditions helped to fuel up the youth unemployment in Sierra Leone as follows:

\section{A. Legacy of the Civil War}

The 11 year civil war, which ended in 2002, have caused a sever destruction and damage on the country's economic facilities, social capital, and physical infrastructures. This has resulted for the displacement of two million people from their livelihood. More than 50,000 people have also lost their life and left many being challenged physically and mentally (NAYCOM, 2013). Illiterate and unskilled young people mainly from rural areas were at the heart of this civil unrest. The war has damaged existing Government systems, structures and frameworks of growth and development. This has also drained the professional pool of the country as people were forced to leave their homeland in search of safety and security.

Agriculture, mining, tourism and other entrepreneurship activities were almost destroyed for lack of peace and stability. Farmers were also forced to abandon their land and their livestock was completely wiped out.

\section{B. Increase in the Youthful Segment of the Population}

There has been a steady increase in youth population over the years from 2008 to 2012 (approximately $34 \%$ of the national population). This increase growth in youth population has led to a massive flow of youth in the labour market that has limited opportunities, creating a divergence between supply and demand. In addition to this, more than $42 \%$ of the country's population is below the age of 15 , sending a signal as the youthful population of the country will continue to swell in the years to come (NAYCOM, 2012).

\section{Rural to Urban Migration}

The migration of young people mainly from rural to urban settings which was accelerated during the civil war has 
increased poverty and socio-economic challenges, which in turn caused degradation on traditional social support systems for youth which led to reduced integrity and low self-esteem among the society. This in general has caused for the accumulation of a huge number of youth in cities, which has less to support employment opportunities.

\section{Mismatch between Demand and Supply of Labour Force}

Shortage and absence of employable and marketable skills due to an ages old educational curriculum is also another factor for youth unemployment. There is a vast difference between the skills that graduates have as compared to the skills needed by the present day labor market. As a result, the country is suffering to meet the growing demand of the skilled labor force in the presently growing extractives sector for instance. Many of the companies are being forced to hire expatriates for even vocational level job opportunities.

The Technical and Vocational Institutions also have very limited programmes that they offer and most of them do not have the capacity to offer quality training programmes as they lack the necessary laboratories, workshops, equipment as well as qualified course instructors. This situation is furthermore exacerbated by the fact that there is no institution in Sierra Leone to train instructors in the vocational stream.

\section{E. Low Level of Institutional Capacity}

The country is emerging from a decade old civil unrest that has wiped out systems, structures, networks and frameworks and as a result of this the different institutions which deal with youth employment suffer from the lack of appropriate capacity to coordinate the youth development sector. The Higher Education sector's capacity is also challenged in offering an education system which matches with the current needs of management, vocational and technical skills needs of the labor force market. Youth serving institutions are still struggling in formulating and enforcing policies, strategies and laws that encourage youth employment.

\section{F. Weak Entrepreneurship Experience}

Many youth lack entrepreneurship experience as an option for self-employment. This sector is also being challenged by limited opportunities for business development services (access to market information, limited access to financial and credit services, absence of innovative orientation, low investment capabilities as a result of weak infrastructure and weak technological capabilities.

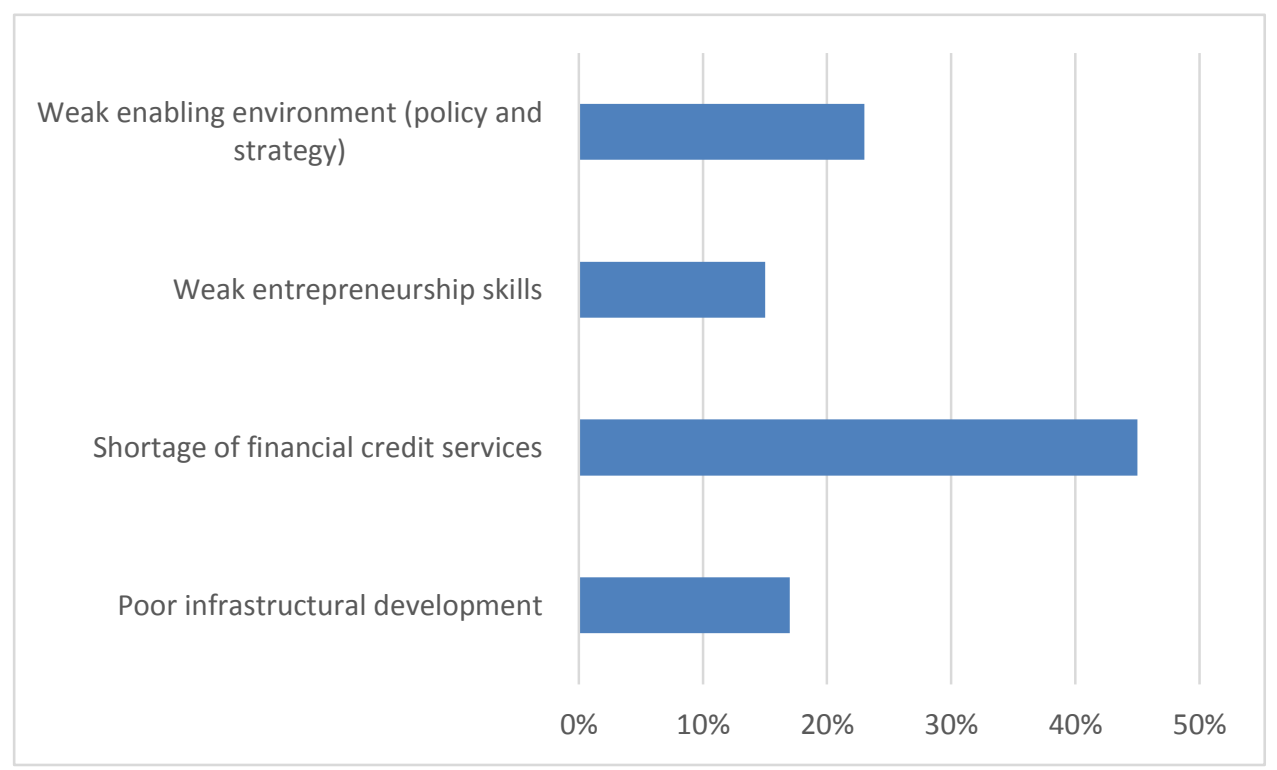

Figure 4. Analysis of Respondents' Response to Factors Affecting Entrepreneurship in Sierra Leone

\section{G. Low Level of Involvement in Agribusiness}

Sierra Leone is endowed with natural resources that can easily be tapped to create employment opportunities. It is however, a sad fact that agricultural activities are being practiced at its minimal. Laurent and Michael (2011) also mentioned that young people in particular who should guarantee and improve its future express reluctance to do this 'slave's work', to 'suffer under the hot sun', 'without harvesting enough to fill the stomach before going to sleep' ${ }^{1}$. This is attributed due to several factors like poor agricultural technology transfer, weak linkage between agriculture and

\footnotetext{
${ }^{1}$ Statements (verbatim) made by young men in informal talks during research in northern Sierra Leone.
} 
research, weak market information management system, etc. which on the other hand is making the sector to be less attractive for the youth to be engaged in.

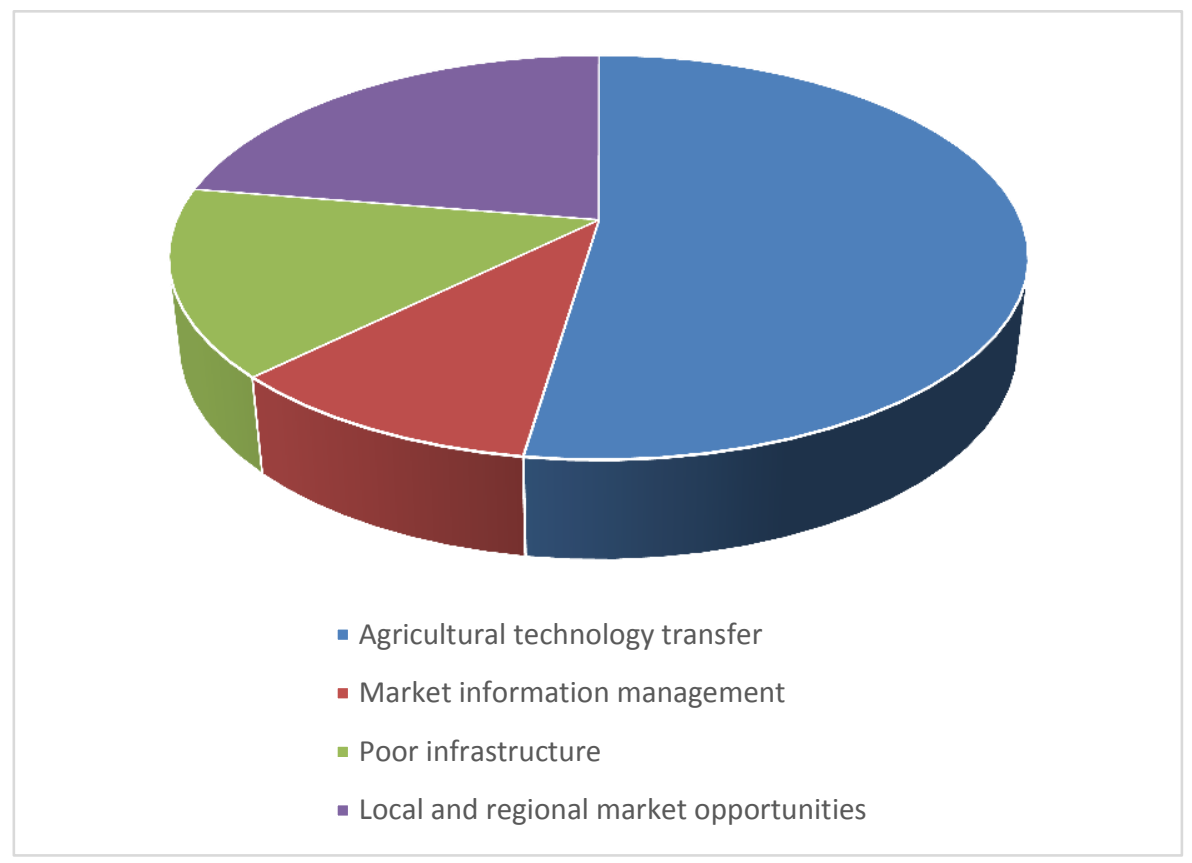

Figure 5. Respondents Analysis on the Magnitude of Factors Affecting Agribusiness

Many of the respondents have also showed very little interest to be engaged in agricultural opportunities which indicates as a lot has to be done if the country has to make the best out of its agricultural potentials.

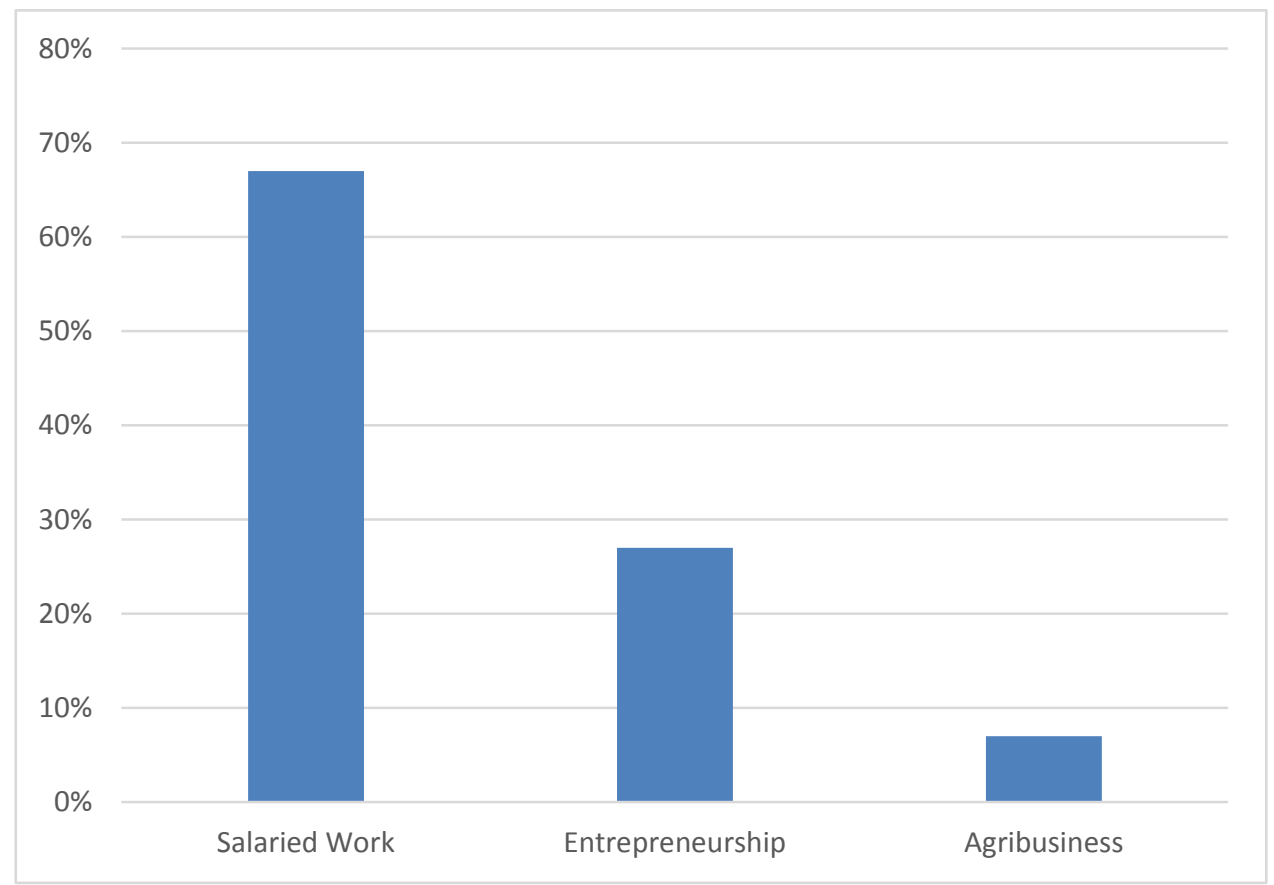

Figure 6. Analysis of Respondents' Preference on Employment Opportunities

\section{H. Insufficient Accesses/Opportunities to Nurture the Talent of Youth}

If tapped properly, youth do have diverse talents that can be turned as an opportunity to manage the development challenges of the country. However, in Sierra Leone, facilities and opportunities to develop the various youth talent from tender age, primary, junior and senior secondary schools, through to higher education institutions rarely exist or 
are inadequate to meet the growing demand. If well managed to develop, talents like skills, sports, arts (drama, music, etc.) could provide channels of employment opportunities for youth.

\section{Discussion}

Based on the findings of the research the application of the following key strategic principles will guide how the Government of Sierra Leone and the different development partners can work towards reducing the high youth unemployment rate and thereof maintaining sustainable development, peace and stability of the country.

\subsection{Guiding Strategic Principles/Mechanisms for Developing Youth Employment Opportunities in Sierra Leone}

\section{A. Opportunities/Strengths based Development Programming Approach}

Every country, locality, family and individuals have its own tapped and untapped resources and potentials which can easily help the wellbeing, growth and development of its own society at large. If potentials are used sustainably, its positive impacts will also have a cross border effect by contributing to the wellbeing of others.

Strengths based approach is an ecological outlook that identifies the significance of people's surroundings and the numerous settings that impact their wellbeing (Saint-Jacques, Turcotte and Pouliot, 2009).

This standpoint identifies the resilience of groups or individuals and gives emphasis on strength, potentials, opportunities, and knowledge instead of looking for the limitations (Grant and Cadell, 2009). It is from this perspective that strengths-based approach is comprehended to diverge from traditional deficit models (Natalie, 2011).

Saint-Jacques, et al., (2009) outlined the strengths-based approach on the following six basic principles:

- Every individual, family, group and community has strengths, and the focus is on these strengths;

- The community is a rich source of resources;

- Interventions are based on client self-determination;

- Collaboration is central with the practitioner-client relationship as primary and essential;

- Outreach is employed as a preferred mode of intervention, and

- All people have the inherent capacity to learn, grow and change.

The approach gives emphasis the capabilities, technical skills, indigenous knowledge, social networks, opportunities and potentials in each individual and group members. It should also be clear that, when focusing on strengths, it does not mean not to consider challenges too. It is also believed that by making use of strengths based approach, there will be a possibility of improving social values and networks that will help the improvement in the wellbeing of others as caring for others can come through improved social networks.

Sierra Leone is endowed with immense natural and human resources which can easily be tapped to ensure the sustainable development of the nation. Therefore, all development initiatives should shift the mind-set away from problem or deficit-focused approaches towards an approach which bases on the available potential resources (labour, fertile land, water resources, forestry, tourism, etc.).

\section{B. Need based Youth Development Approach}

The needs-based approach, which defines poverty as 'the absence or lack of the basic elements required for human survival', was used as an appropriate model to enhance growth and development in Africa during the course of the 1950s and 1960s (Booy et al., 2000).

Development denoting change or progress in the wellbeing of humans has now been acknowledged as a multidimensional concept. The principal aim and outcome of wealth and livelihoods creation as a measure of unidimensional concept of development, in turn, is said to have been achieved by production for profit alone. According to Ataul (1996), the production for profit could be pursued only by those producers who would be guided by self-interested motives of maximizing output and minimizing costs.

Thus, youth focused development interventions should be informed by evidence to ensure that interventions are of the scale required, and that implementation is monitored and evaluated for sustainability, effectiveness and impact. The views, aspirations and needs of young people should be valued and considered before making any decision that concerns them both at macro and micro level issues. As the female youth do face a great challenge in employment opportunities, their views and needs have to be treated equally like their male counterpart.

\section{Participation and National Ownership}

The achievements of developmental goals could entail the involvement of different parties like Government institutions, Civil Society Organizations, development partners, individuals, communities, the private sector, legislatives, academia, 
etc. It is however, imperative for the outcomes of developmental endeavors to be embraced by the national society. This can only happen so long as development programmes are holistic and participatory from their conception to design, implementation, monitoring and evaluation stages of development programmes. Institutions shape incentives that may influence the stakeholder ownership for a given development goal (Nicola, 2011).

Youth focused development initiatives should specifically emphasize on the participation of young people, which is a key tool to ensure the development initiatives respond positively to their specific needs, and that will enable them to own the outcomes at the end of the day. In doing so, they will be positively engaged in the activities that will affect their environments which in turn can lead to the buildup of positive networks, influence and quality relationships within their community.

\section{Development of Coordination Framework}

The coordination of developmental efforts has to be dominated by government bodies taking the lead and the driver's seat so that outcomes can easily be internalized and assimilated in a sustainable way. Government bodies should be able to lead the proper design, implementation and monitoring of developmental prpgrammes by making the felt needs and aspirations of the community central to their development goals. Development partners should also focus on strengthening leadership, systems, structures and frameworks so that the impact of their investment can last long (WHO, 2009).

In order to achieve sustainability, youth development interventions in particular should adopt effective and trusting partnerships between young people and their communities, institutions, agencies and governments so as to facilitate integrated multi-sectorial and multi-level commitment towards the achievement of national development goals. This will also help in having a common goal, shared vision and in avoiding duplication of efforts and resources.

\section{E. Institutional Capacity Building}

The 11 year civil war has greatly destroyed systems, networks and different government structures. The country is still striving to establish different ministerial bodies so as to coordinate the development of the country. Therefore, in line with this, youth serving institutions like the newly established Ministry of Youth Affairs and the National Youth Commission needs to have the required human, technical, and material capacities so that they will be in a position to coordinate and lead youth development efforts of the country. Youth development policies and strategies need to be developed and implemented as a matter of urgency. There is also a heightened need for the establishment and strengthening of grass root level institutional bodies, so that the youth can easily be mobilized to participate in the development of the nation.

\section{F. Inclusive Growth and Sustainable Development Approach}

Growth and developmental efforts should consider the diverse needs and circumstances of young people along with gender related perspectives and other factors by facilitating inclusive mechanisms and providing targeted responses to address their specific challenges will help to contribute for a sustained development.

Development initiatives should also embrace and integrate social, environmental, economic, political and cultural perspectives by gearing efforts towards efficient management of resources by enhancing the resilience of its people and future generations from different shocks and crisis.

\section{G. Increased Creativity and Innovation}

Developing countries are being challenged for lack of the system to encourage their human capital in solving developmental challenges and problems. Humans do have indigenous technical knowledge that has evolved over years. Humans can also influence challenges of life if they get creative and innovative ways of building their resilience. Policies and the formulation of corresponding strategies that encourage creativity and innovation will have a broader impact in the realization of economic growth.

OECD (2012) mentioned that, in the 1960s Green Revolution of India, the development of improved technologies like improved seeds, improved crop management practices, the development of irrigation systems, machineries, etc. helped to maximize agricultural production and productivity of the nation. This has also helped the country to fight against food and nutrition insecurity. Yet, innovation happens in different areas of entrepreneurship, industrial development, health and other human development related issues.

Due to age and other related factors, young people love to create and see new things and technologies which can easily tap their attention. Therefore, development interventions need to explore creative and independent paths of thinking whereby the creativity and innovation potentials of young people can be planned, communicated, and implemented in an efficient way for the betterment of themselves and their society.

\section{H. Creation of Enabling Environment}


Among others, the design and implementation of youth friendly policy and strategies can help the creation of conducive environment so as to intensify the development of the youth in an efficient way. Greater emphasis should be given to the formulation and enforcement of labour market policies, local content policy, encouraging the development of self-employability skills, microfinance development, entrepreneurship development, addressing the skills mismatch between the demand and supply side of the labor force, apprenticeships and internships, and agribusiness development are among the issues that will help the creation of the enabling environment for the efficient development of youth employment and empowerment potentials of the country.

I. Monitoring and Evaluation

For the successful implementation of development programmes, monitoring and evaluation exercises should form an integral part of the entire programme cycle. Periodic reviews, regular tracking of the changes achieved, documenting and sharing best practices are some of the activities that could form the monitoring and evaluation framework of development programmes.

\section{Conclusion}

Youth in Sierra Leone are being faced with high rates of inactivity, underemployment and unemployment, poor working conditions compounded with long hours and low rate of payment for their services. They also faced mounting problems of poor quality education, skills mismatch so as to cope up with the labour market, poor health and nutritional standards and mounting social development challenges including teenage pregnancy, drug abuse, violence and crime. The legacy of the 11 years civil war has also disrupted the livelihoods of many and more than $60 \%$ of the country's youth are believed to structurally unemployed and $50 \%$ of the country's youth are classified as either unskilled or illiterate.

The presence of a large number of unemployed youth can be a threat to the peace and stability of any nation given their vulnerability to recruitment into criminal and violent activities.

If used properly, youth are also a prime human capital that can transform the wellbeing a nation as they are highly enthusiastic and possess the zeal and aptitude to pursue their own development, however it is necessary for the government institutions such as the National Youth Commission and Ministry of Youth Affairs to bring key partners on board and put hands together in a coordinated way if the country's youth unemployment has to be minimized.

\section{References}

AfDB (African Development Bank Group) (2011). The Bank and the Agenda for Inclusive Growth, Lisbon.

AfDB (African Development Bank Group) (2012). Green Growth: Perspectives For Africa and the AFDB in the 21st Century, Briefing Notes for AFDB's Long Term Strategy, 8.

AfDB (African Development Bank Group) (2013). Sierra Leone Country Strategy Paper, 2013-2017, Sierra Leone, Freetown.

Andrew, N., \& Andrew, R. (2012). Inclusive and Sustainable Development: Challenges, Opportunities, Policies and Partnerships; Two Challenge Papers by Denmark, ODI.

Ataul, H. (1996). Need Based Development and Its Implications for Sustainability, Humanomics, 12(2), Department of Economics, International Islamic University, Petaling Jaya, Malaysia.

Babatunde, O. (2014). Inclusive Green Growth in Africa: Rationale, Challenges and Opportunities, United Nations Development Programme, South Africa.

Blaxter, L., Christina, H., \& Malcolm, T. (2001). Hope Up Study Skills, How to Research, Open University Press, Mc Graw Hill Education House, England, United Kingdom.

Boeije, H. (2010). Analysis in qualitative research (1st ed.). Los Angeles: SAGE.

Booy, D., Sena, O., \& Arusha, S. (2000). Capacity Building using the Appreciative Inquiry Approach: The experience of world vision Tanzania. Global Social Innovations, Journal of the GEM Initiative, 3.

Christopher Woodruff (2007). Self-Employment: Engine of Growth or Self-Help Safety Net?, Washington.

Cohen, D., \& Crabtree, B. (2006). Qualitative Research Guidelines Project.

http://www.qualres.org/HomeTria-3692.html accessed on February 26, 2016 at 09:20PM.

DFID (2008). Jobs, labour Markets and Shared Growth, Trends and Issues.

Eastwood, R., \& Lipton, M. (2000). Pro-Poor Growth and Pro-Growth Poverty Reduction: Meaning, Evidence and Policy Implications, Asian Development Review, 2.

Flick, U., Kardorff, E., \& Steinke, I. (2004). A companion to qualitative research ( $1^{\text {st }}$ ed.). London: Sage Publications. 
GoSL (Government of Sierra Leone) (2003). Sierra Leone National Youth Policy, Freetown, Sierra Leone.

GoSL (Government of Sierra Leone) (2014). National Youth Development Coordination Framework, Freetown, Sierra Leone.

GoSL and UNDP (Government of Sierra Leone and UNDP) (2013). National Youth Employment Programme (2014-2018), Freetown, Sierra Leone.

Grant, J. G., \& Cadell, S. (2009). Power, Pathological Worldviews, and the Strengths Perspective in Social Work. Families in Society.

ILO (2012). Statistical Update on Employment in the Informal Economy, ILO - Department of Statistics.

ILO (2014). Global employment trends 2014: Risk of a jobless recovery? International Labour Office. Geneva

Kakwani, N., M., \& Neri, H. S. (2004). Linkages between Pro-Poor Growth, Social Programmes and Labour Market: The Recent Brazilian Experience.Working Paper. UNDP International Poverty Center, Brazil.

Krippendorff, K., \& Mary, A. B. (1990). Content Analysis Reader, Sage publication, California, USA.

Laurent, E. C., \& Michael, B. (2011). Agriculture and Artisanal Mining in Sierra Leone: Alternatives or Complements? Journal of International Development, 23, 1080-1099. Published online in Wiley Online Library. http://dx.doi.org/10.1002/jid.1833

Munn, P., \& Drever, E. (1990) Using Questionnaires in Small-scale Research: A Teacher's Guide. Edinburgh: Scottish Centre for Research in Education.

Natalie, S. (2011). Strengths-Based Practice: The Evidence. UnitingCare Children, Young People and Families, Parramatta NSW 2150.

NAYCOM (2013b). Agribusiness and Rural Entrepreneurship Development for Youth Employment in Sierra Leone. Project Document. Freetown, Sierra Leone.

NAYCOM (National Youth Commission) (2012). Sierra Leone Status of Youth Report, Sierra Leone, Freetown.

NAYCOM (National Youth Commission) (2013). Sierra Leone Status of Youth Report, Sierra Leone, Freetown.

NGS (National Geographic Society), (2015). http://travel.nationalgeographic.com/travel/countries/sierra-leone-facts/

Nicola, S. (2011). The Importance of Stakeholder Ownership for Capacity Development Results. World Bank Institute Capacity Development and Results, Washington, D.C. 20433, USA.

OECD (Organisation for Economic Co-operation and Development) (2012). Innovation for Development. A Discussion of the Issues and an Overview of Work of the OECD Directorate for Science, Technology and Industry.

Pierella, P., \& Pieter, S. (2007). Employment and Shared Growth Rethinking the Role of Labor Mobility for Development, Washington.

Robson, C. (2002). Real World Research, A Resource for Social Scientists and Practitioner-Researchers, Blackwell Publishers, USA.

Roulston, K. (2001). Data analysis and 'theorizing as ideology'. London Thousand Oaks, CA and New Delhi), 1(3), 279-302.

Saint-Jacques, M., Turcotte, D., \& Pouliot, E. (2009). Adopting a Strengths Perspective in Social Work Practice with Families in Difficulty: From theory to practice. Families in Society, 90(4). http://dx.doi.org/10.1606/1044-3894.3926

Saunders, M., Lewis, P., \& Thornhill, A. (2000). Research Methods for Business, (2nd Edition), Pearson Education Limited, Essex, UK.

Siraj-Blatchford, I., \& Siraj-Blatchford, J. (2001). Survey and Questionnaires: An Evaluation Case Study, Buckingham; Open University, United Kingdom.

SSL and UNDP (2014). Statistics Office of Sierra Leone and United Nations Development Programme: Employment and Time use Module of the Sierra Leone Integrated Household Survey 2003-2014, Freetown, Sierra Leone.

Todd, D. J. (1979). Mixing Qualitative and Quantitative Methods: Triangulation in Action, Administrative Science Quarterly, 24(4), Qualitative Methodology, Cornell University.

UNESEC (2011). A Green Economy in the Context of Sustainable Development and Poverty Eradication: What are the Implications for Africa? Background report Africa Regional Preparatory Conference for the United Nations Conference on Sustainable Development "Rio+20", Addis Ababa, Ethiopia. 
WB (World Bank Group) (2012). Inclusive Green Growth: The Pathway Sustainable Development, The World Bank, Washington, USA.

Weber, Philip (1990). Basic Content Analysis, Sage Publication, California, USA. http://dx.doi.org/10.4135/9781412983488

WHO (World Health Organization) (2009). Review of Coordination Mechanisms for Development Cooperation in Tajikistan. WHO Regional Office for Europe Scherfigsvej 8, DK-2100 Copenhagen, Denmark.

\section{(c) $)$ EY}

This work is licensed under a Creative Commons Attribution 3.0 License. 